\title{
SUMO proteins are involved in the stress response during spermatogenesis and are localized to DNA double-strand breaks in germ cells
}

\author{
Vibha Shrivastava ${ }^{1}$, Marina Pekar ${ }^{1}$, Eliana Grosser $^{1}$, Jay $\operatorname{Im}^{1}$ and Margarita Vigodner ${ }^{1,2}$ \\ ${ }^{1}$ Department of Biology, Stern College for Women, Yeshiva University, 245 Lexington Avenue, New York, New York \\ 10016, USA and ${ }^{2}$ Department of Developmental and Molecular Biology, Albert Einstein College of Medicine, \\ Yeshiva University, Bronx, New York 10461, USA \\ Correspondence should be addressed to M Vigodner at Department of Biology, Stern College for Women, Yeshiva University; \\ Email:vigodner@yu.edu
}

\begin{abstract}
Small ubiquitin-like modifiers (SUMO) proteins have been implicated in cellular stress response in different tissues, but whether sumoylation has a similar role during spermatogenesis is currently unknown. In this study, changes in the levels of both free SUMO isoforms and high-molecular weight (HMW) SUMO conjugates were monitored before and after the induction of different types of cellular stresses. Using cell lines and primary cells freshly isolated from mouse testes, significant changes were detected in the levels of SUMO1 and SUMO2/3 conjugates following short exposure of the cells to heat stress and oxidative stress. While high concentrations of $\mathrm{H}_{2} \mathrm{O}_{2}$ caused an increase in protein sumoylation, low concentrations of $\mathrm{H}_{2} \mathrm{O}_{2}$ mostly caused protein desumoylation. Immunofluorescence studies localized SUMO to the sites of DNA double-strand breaks in stressed germ cells and during meiotic recombination. To study the effect of oxidative stress in vivo, animals exposed to tobacco smoke for 12 weeks were used. Changes in sumoylation of HMW proteins were consistent with their oxidative damage in the tobacco-exposed mice. Our results are consistent with the important roles of different SUMO isoforms in stress responses in germ cells. Furthermore, this study identified topoisomerase $2 \alpha$ as one of the targets of sumoylation during normal spermatogenesis and under stress.

Reproduction (2010) 139 999-1010
\end{abstract}

\section{Introduction}

Adult spermatogenesis consists of three phases: proliferation of spermatogonia, meiosis of spermatocytes, and differentiation of spermatids or spermiogenesis. These events are precisely controlled at each stage to ensure the formation of genetically balanced gametes. Posttranslational modification by small ubiquitin-like modifiers or SUMO proteins has been identified as an important regulatory event implicated in several cellular processes, including transcriptional regulation, protein stability, stress-induced responses, cell cycle progression, and the DNA repair process (Ayaydin \& Dasso 2004, Gill 2004, Muller et al. 2004, Zhao 2007, Dasso 2008). Covalent addition of SUMO (sumoylation) with the formation of an isopeptide bond on a lysine residue of the target protein often, but not always, occurs within a SUMO consensus motif, and it involves maturation, activation, conjugation, and ligation steps mediated by specific protein complexes (E1, E2, and E3). Sumoylation is reversed through the action of sentrinspecific proteases that cleave the isopeptide bond between SUMO and its substrate (Ayaydin \& Dasso
2004, Gill 2004, Muller et al. 2004, Geiss-Friedlander \& Melchior 2007, Zhao 2007, Dasso 2008). Four SUMO paralogs have been identified: SUMO1, SUMO2, SUMO3 (often termed as SUMO2/3 because of their 95\% sequence identity), and SUMO4, which may have common and distinct targets and functions within cells. While SUMO1, SUMO2, and SUMO3 are abundantly expressed in different tissues, SUMO4 is restricted to the kidney, liver, and lymph nodes (Bohren et al. 2004, Dohmen 2004, Li et al. 2005). In addition to numerous identified targets of sumoylation, there is a growing list of proteins that interact with SUMO noncovalently through a SUMO-interacting motif (Song et al. 2004, 2005, Chupreta et al. 2005, Lin et al. 2006, Kerscher 2007). Furthermore, a phosphorylation-dependent sumoylation motif has been discovered, supporting a complex interplay between different posttranslational modifications (Hietakangas et al. 2006). Covalent and noncovalent SUMO binding to a target protein can modify the protein's activity, localization, and its ability to bind to other proteins or DNA. The exact model of how SUMO regulates these functions is largely unknown. 
SUMO1 and SUMO2/3 have been recently studied during mouse and human spermatogenesis, where they were localized to different subdomains of germ and somatic testicular cells (Rogers et al. 2004, Vigodner \& Morris 2005, Vigodner et al. 2006, Brown et al. 2008,
Metzler-Guillemain et al. 2008, Vigodner 2009). This localization pattern is suggestive of multiple and nonidentical roles of SUMO in mitotic spermatogonia, meiotic spermatocytes, and differentiating spermatids. Consequently, a recent study showed differential
A

SUMO2/3

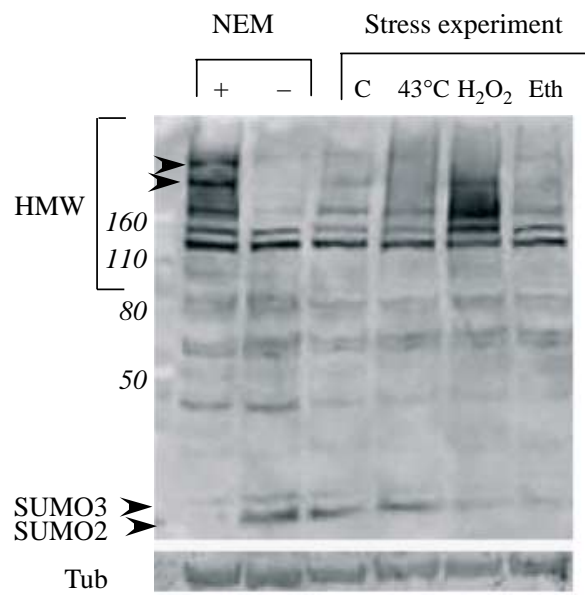

HMW SUMO2/3

conjugates

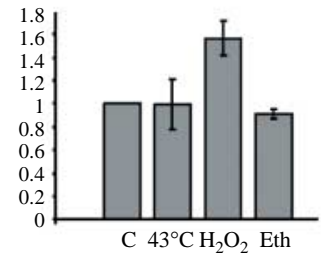

D

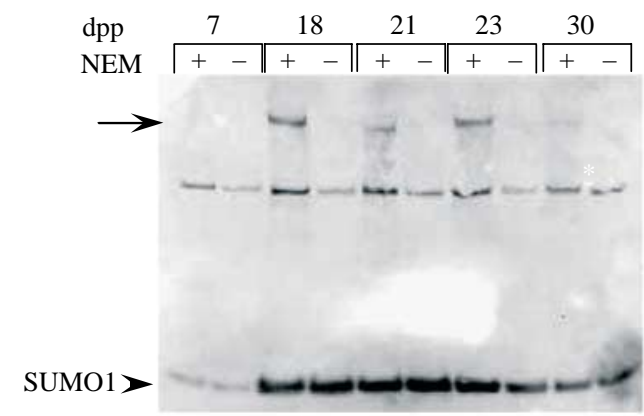

Tub

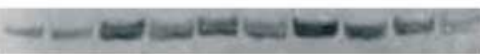

$\mathrm{E}$

E

BLOT

SUMO $2 / 3$
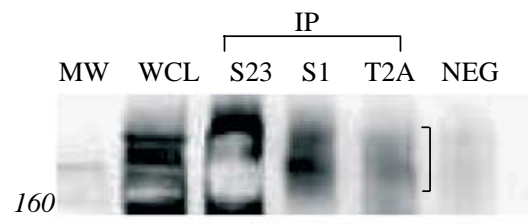

160

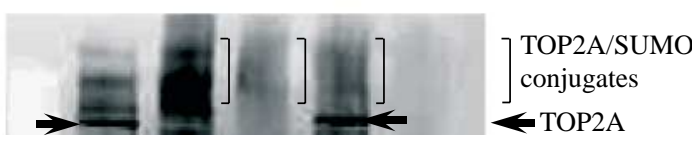

B SUMO1

TOP2A
TOP2A/SUMO
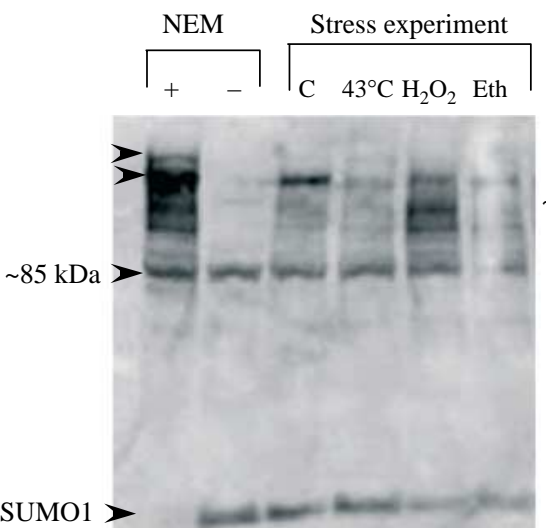

Free

SUMO2/3

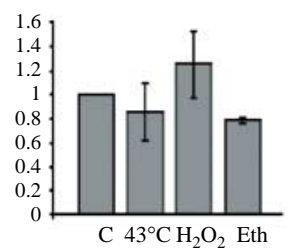

SUMO1

conjugates

F

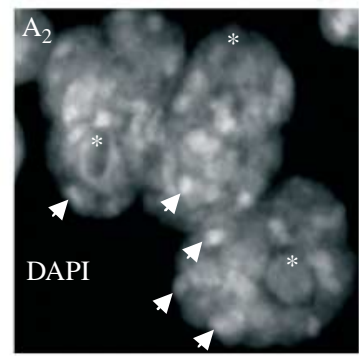

$\mathrm{B}_{1}$
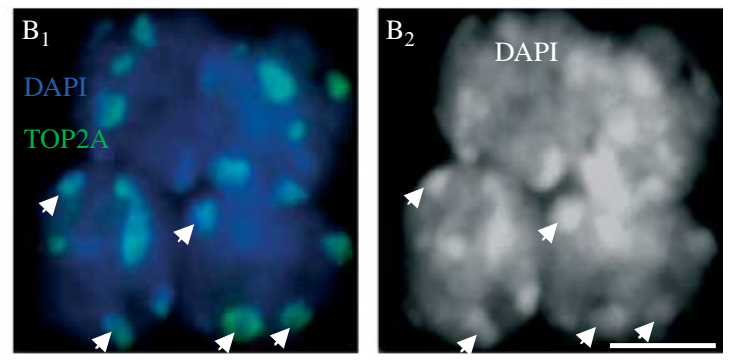
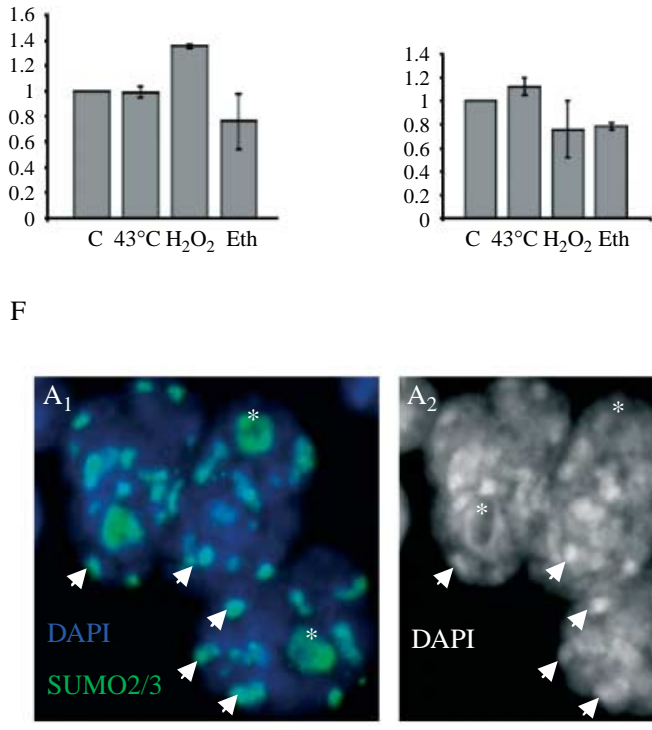

Free SUMO1

HMW SUMO1

conjugates

C TOP2A
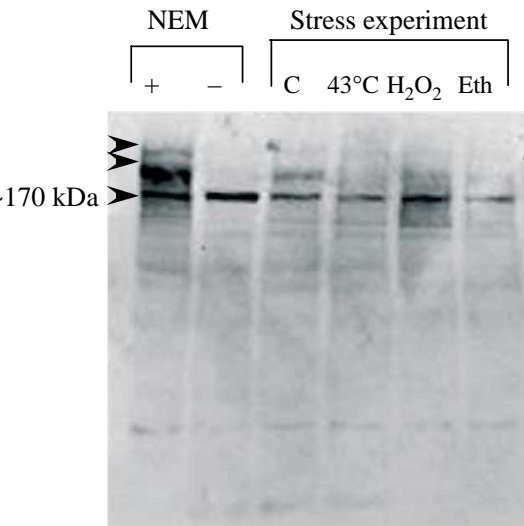
expression patterns of genes related to the sumoylation pathway in different germ cell populations, but little is still known about the regulation of spermatogenesis by sumoylation (La Salle et al. 2008). The localization pattern of SUMO1 and SUMO2/3 in the testis appeared not to be fully overlapping, although a recent study using SUMO1 knockout mice does not support differential roles of the SUMO isoforms during spermatogenesis (Zhang et al. 2008).

Male fertility has become a concern during recent decades. The overall sperm decline has been attributed to different environmental factors such as elevated scrotal temperature, increased levels of reactive oxygen species, alcohol abuse, and smoking (Anderson et al. 1983, Sikka 1996, Emanuele \& Emanuele 1998, Lue et al. 1999, 2000, Rockett et al. 2001, Dare et al. 2002, Agarwal et al. 2003, 2006, Aitken et al. 2003, Muthusami \& Chinnaswamy 2005, Aitken \& De luliis 2007, Aitken \& Roman 2009). An understanding of the stress response in germ cells is of crucial importance because genetic damage, such as DNA breaks, can lead to cancer or to the transmission of the affected DNA to the next generation.

In other tissues, SUMO proteins have been found to be involved with responses to cellular stresses, including oxidative, temperature, ethanol, and genotoxic stresses (Saitoh \& Hinchey 2000, Tempe et al. 2008, Golebiowski et al. 2009). Whether sumoylation has a similar role in testicular cells is currently unknown. To address this and other questions regarding the role of sumoylation during spermatogenesis, we designed a series of experiments in which changes in the levels of both free SUMO isoforms and high-molecular weight (HMW) SUMO conjugates were compared before and after the induction of different types of cellular stresses. Our results are consistent with important roles of different SUMO isoforms in stress responses during spermatogenesis. Furthermore, this study suggests specific targets of sumoylation in normal testis and under stress.

\section{Results}

\section{Western blot analysis of SUMO expression in freshly isolated mouse testicular cells}

To gain insights into a possible role of sumoylation in the stress response during spermatogenesis, western blot analyses were employed to compare the levels of free SUMO and its HMW conjugates in cells equilibrated in the culture medium and subjected to heat, oxidative, and ethanol stresses. In Fig. $1 \mathrm{~A}-\mathrm{C}$, the stress experiment (lanes 3-6) is shown alongside protein samples prepared immediately after the animals were killed either using or not using the isopeptidase inhibitor $\mathrm{N}$-ethylmaleimide (NEM), which prevents cleavage of SUMO from the target proteins (lanes 1 and 2 respectively). SUMO2 and SUMO3 are $95 \%$ homologous and are detectable with the same antibody. However, the two proteins can be resolved on a gel because of their slightly different molecular weights. Both SUMO1 and SUMO2/3 antibodies detected bands of the size predicted for free SUMO isoforms ( $\sim 15 \mathrm{kDa}$ for SUMO1, and $\sim 15$ and $18 \mathrm{kDa}$ for SUMO2 and SUMO3 respectively) and HMW SUMO conjugates (Fig. 1A and B). Most of the HMW SUMO conjugates were NEM sensitive, although there were a few (such as apparently SUMO1-modified RANGAP1, the major specific SUMO1 band at $\sim 85 \mathrm{kDa}$ ) that were not (Fig. 1B, Matunis et al. 1996). In the absence of NEM, a major increase in the level of free SUMO1 and SUMO2 was detected, a finding that suggests a specific role for SUMO1 and SUMO2 in testicular cells. Unless indicated, NEM was added to the lysis buffer.

The exposure of cells to heat (Fig. $1 \mathrm{~A}$ and $\mathrm{B}, 43^{\circ} \mathrm{C}$ ) did not cause significant changes in global sumoylation compared with the control (control, C), but caused changes in the level of individual SUMO2/3 and SUMO1 targets. Following the exposure of cells to oxidative stress $\left(\mathrm{H}_{2} \mathrm{O}_{2}\right)$, a rapid increase in the overall level of HMW SUMO2/3 and SUMO1 conjugates was observed compared with the untreated cells $(P<0.05)$,

Figure 1 (A-C) Effects of stress on SUMO2/3, SUMO1, and TOP2A protein expression in testicular cells. After equilibrating in the culture medium, the cells were exposed to heat $\left(43^{\circ} \mathrm{C}\right), \mathrm{H}_{2} \mathrm{O}_{2}(100 \mathrm{mM})$, or ethanol (Eth, $7 \%$ ) for $20 \mathrm{~min}$ followed by the preparation of whole cell lysates using the isopeptidase inhibitor NEM (Stress experiment). The stress experiment (lanes 3-6) is shown alongside protein samples prepared immediately after the animals were killed either using or not using NEM (lanes 1 and 2). Western blotting was performed using anti-SUMO2/3 antibody (A) followed by stripping and reincubation of the membrane with either SUMO1 (B) or TOP2A (C) antibodies. Free SUMO isoforms (arrowheads) and highmolecular weight SUMO conjugates (HMW) are shown. The $85 \mathrm{kDa}$ band corresponds to SUMO1-conjugated RANGAP (B); the $170 \mathrm{kDa}$ band corresponds to unmodified TOP2A (C). Arrowheads in A-C indicate possible sumoylated forms of TOP2A. The positions of 50, 80, 110, and 160 kDa molecular weight markers are indicated in A. Equal loading was determined using MAB anti- $\beta$-tubulin (Tub). Densitometry results for the level of free SUMO and HMW SUMO conjugates are shown from three independent experiments after normalization to tubulin. (D) Analysis of SUMO1 conjugation during the first spermatogenic wave. Testicular cells were isolated from pubertal mice on days 7, 18, 21, 23, and 30 post partum (dpp) during the first spermatogenic wave. Protein lysates were prepared with or without NEM. The arrow indicates a prominent NEM-sensitive HMW SUMO1 conjugate, which was absent in mitotic spermatogonia (day 7) but appeared in meiotic spermatocytes (days 18 and 21 ). The level of the protein decreased as the cells progressed through spermiogenesis (from day 23 to 30). (E) TOP2A is sumoylated in testicular cells. Testicular cell lysates were immunoprecipitated using antibodies against SUMO23 (S23), SUMO1 (S1), and TOP2A, followed by western blot analyses with anti-SUMO2/3 (upper panel) or anti-TOP2A (lower panel) antibodies. Molecular weight markers (MW), whole cell lysate (WCL), and negative control without antibodies (NEG) are shown. (F) SUMO2/3 and TOP2A are localized to centromeric heterochromatin in meiotic spermatocytes. Images $A_{2}$ and $B_{2}$ are identical fields to $A_{1}$ and $B_{1}$ respectively using DAPI staining alone. Arrows indicate localization of SUMO2/3 (green, $A_{1}$ ) and TOP2A (green, $B_{1}$ ) to centromeric heterochromatin intensely stained by DAPI. SUMO2/3 also localizes to the sex body area (asterisk, A). The scale bar is $10 \mu \mathrm{m}$. 
while changes in the level of some individual SUMO targets were detected after 20-min treatments with ethanol (Eth). Densitometry results obtained from three experiments are shown after normalization to tubulin. Differently from the study in somatic cells (Saitoh \& Hinchey 2000), no apparent invert correlation was obtained between the level of free SUMO and HMW conjugates after an increase in global sumoylation following the oxidative stress. This could be partially explained by a stress-induced activation of SUMO2/3 transcription in some testicular cells, as will be demonstrated below (Fig. 2). The invert correlation can clearly be detected in lanes 1 and $2(+/-N E M)$, supporting the sensitivity of the assay. Interestingly, the level of HMW SUMO conjugates was significantly higher in the freshly prepared sample (+NEM) than in the control one $(\mathrm{C})$ prepared from the cells incubated for $2-3 \mathrm{~h}$. This finding may indicate either a SUMOmediated stress response by hypoxia following the $\mathrm{CO}_{2}$ animal asphyxiation, and/or possible changes in protein expression upon maintaining germ cells ex vivo.

Overall, SUMO1 and SUMO2/3 immunoblots were not identical. Some HMW bands were recognized by both antibodies, and some were detectable exclusively by either anti-SUMO1 or anti-SUMO2/3 (Fig. 1A and B). Furthermore, analysis using cells isolated from the testis of pubertal mice during the first spermatogenic wave revealed the presence of germ cell-specific SUMO targets. In Fig. 1D, for example, an arrow indicates a prominent NEM-sensitive HMW SUMO1 conjugate which was absent in mitotic spermatogonia (day 7), but which appeared in meiotic spermatocytes (days 18 and 21). The level of the sumoylated protein decreased as the cells progressed through spermiogenesis (from day 23 to 30). Therefore, further studies are needed to identify this and other cell-specific SUMO conjugates, as well as to differentiate between stress responses in different types of testicular cells.

\section{Topoisomerase $2 \alpha$ is a possible sumoylation target in testicular cells}

Topoisomerases are one of the major SUMO targets in mitotic cells, in which they were also implicated in stress response. A specific topoisomerase isoform, topoisomerase $2 \alpha$ (TOP2A), was abundantly expressed in germ cells, especially during meiosis (Cobb et al. 1999), and the protein localization pattern partially resembled that of SUMO. As has been reported previously, in meiotic spermatocytes, SUMO localized to the inactivated sex chromosome (sex body) region (Fig. $1 \mathrm{~F}$, panels $A_{1}$ and $A_{2}$, asterisk; Rogers et al. 2004, Vigodner \& Morris 2005) and regions of centromeric heterochromatin, which were intensely stained by
A

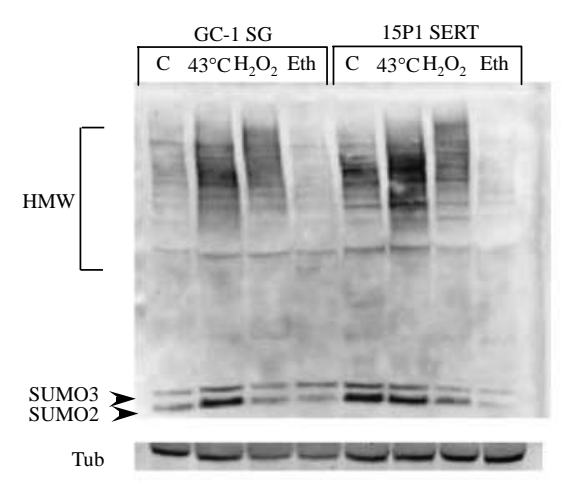

GC-1 SG

HMW SUMO2/3 conjugates

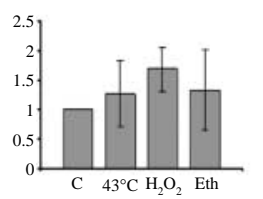

Free SUMO2/3

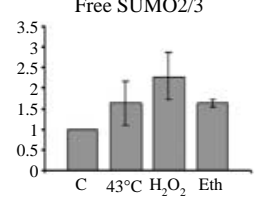

15 P1 SERT

HMW SUMO $2 / 3$ conjugates

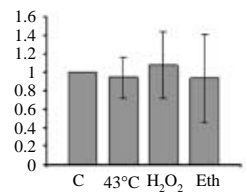

Free SUMO $2 / 3$

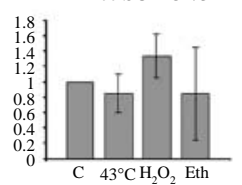

B

SUMO
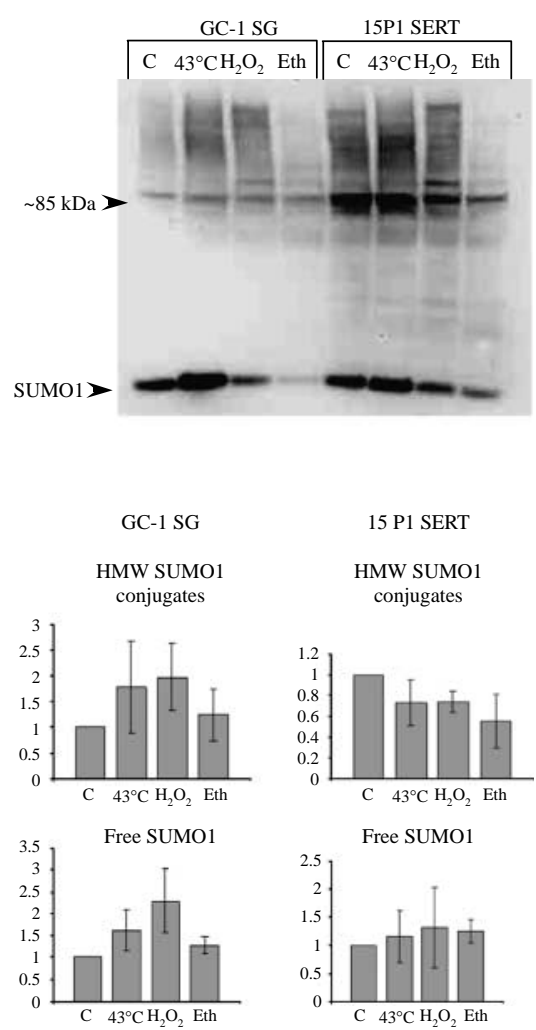

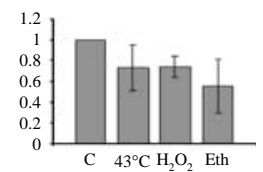

Free SUMO1

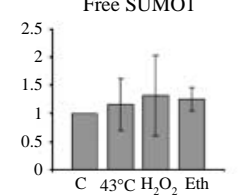

Figure 2 Effects of stress on SUMO2/3 and SUMO1 protein expression in GC-1 spermatogonia and 15P1 Sertoli cells. Cells were treated with heat $\left(43^{\circ} \mathrm{C}\right), \mathrm{H}_{2} \mathrm{O}_{2}(100 \mathrm{mM})$, or ethanol (Eth, 7\%) for $20 \mathrm{~min}$. Whole cell lysates were prepared with the isopeptidase inhibitor NEM. Free SUMO isoforms (arrowheads) and high-molecular weight SUMO conjugates (HMW) are shown. The $85 \mathrm{kDa}$ band corresponds to SUMO1-conjugated RANGAP. Equal loading was determined using MAB anti- $\beta$ tubulin (Tub). Densitometry results for the level of free SUMO and HMW SUMO conjugates are shown from three independent experiments after normalization to tubulin. 
4,6 diamino-2-phenylindole (DAPI; arrows). TOP2A was also mostly concentrated in the area of centromeric heterochromatin (Fig. $1 \mathrm{~F}$, panels $\mathrm{B}_{1}$ and $\mathrm{B}_{2}$, arrows), but it was also detectable at low level along the chromosome axes in the whole nucleus. Localization of both SUMO and TOP2A to centromeric heterochromatin suggested a possible interaction of the two proteins in the germ cells. To test this hypothesis, the protein pattern obtained on SUMO1 and SUMO2/3 immunoblots was compared to that obtained after the incubation of the same membrane with the antibody against TOP2A. Several specific bands were detected using anti-TOP2A antibody, and the major band corresponded to unmodified TOP2A (170 kDa, Fig. 1C). Higher molecular weight conjugate(s) were NEM sensitive and apparently represented the sumoylated form of the protein as they were also recognized by SUMO1 and SUMO2/3 antibodies (Fig. 1A-C, arrowheads). Consistent with this suggestion, as the modified form(s) disappeared in the absence of NEM, the major $170 \mathrm{kDa}$ TOP2A band became more prominent (Fig. 1C). We confirmed these results using co-immunoprecipitation assay, and were able to coimmunoprecipitate SUMO with anti-TOP2A antibody and vice versa (Fig. 1E).

\section{Western blot analysis of SUMO expression in GC-1 spermatogonia and 15P1 Sertoli cells}

In the initial steps in the characterization of cell-specific response in testicular cells, two cell lines, GC-1 spermatogonia (Spg) cells and 15P1 Sertoli cells, were employed (see Materials and Methods). As shown in
Fig. 2A and B, GC-1 spermatogonia cells showed an increase in HMW SUMO1 and SUMO2/3 conjugates noticeable in the cells that underwent heat and oxidative stress $(P<0.05)$. While GC- 1 cells showed prominent stress-induced changes in global sumoylation, no statistically significant changes were detected in 15P1 Sertoli cells. Interestingly, differently from previously described phenomenon when the level of free SUMO gradually decreased as other proteins became sumoylated, in the cell lines used herein, certain stresses apparently also caused an increase in the level of free SUMO (mostly SUMO2 and SUMO1). This finding may suggest a possible very rapid activation of SUMO transcription and translation following the induction of the stress. Differently from heat and $\mathrm{H}_{2} \mathrm{O}_{2}$-induced stresses, ethanol caused no statistically significant changes in HMW SUMO conjugates. Further studies using enriched cell populations of testicular cells are needed to confirm this finding and to get more insights into the mechanism of cell-specific stress response during spermatogenesis. However, such studies can be compromised by time-consuming separation procedures and instability of SUMO conjugates.

\section{Effect of different concentrations of $\mathrm{H}_{2} \mathrm{O}_{2}$ on sumoylation in testicular cells}

Initial experiments employed stress conditions that have been used previously to study sumoylation in somatic cells (Saitoh \& Hinchey 2000). In these experiments, the concentration of $\mathrm{H}_{2} \mathrm{O}_{2}$ was very high, hardly reached in vivo. It has been recently reported that testicular cells are extremely sensitive to very low concentrations of
A

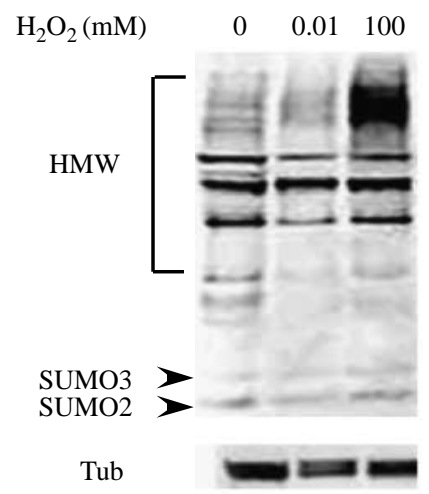

HMW SUMO2/3 conjugates

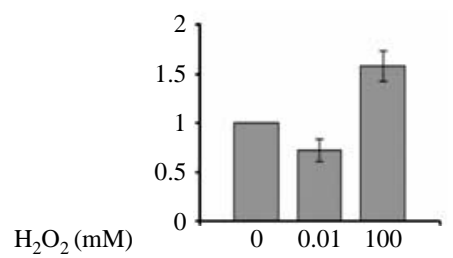

www.reproduction-online.org
B SUMO1

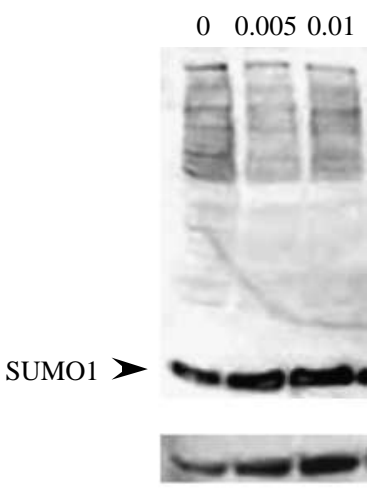

HMW SUMO1 conjugates

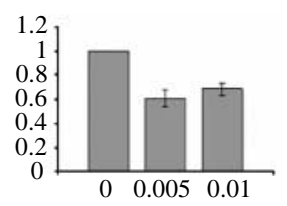

Figure 3 Effects of low and high concentrations of $\mathrm{H}_{2} \mathrm{O}_{2}$ on protein sumoylation in testicular cells. Cells were treated with the indicated concentrations of $\mathrm{H}_{2} \mathrm{O}_{2}$ followed by the preparation of whole cell lysates in the presence of NEM. Two different experiments are shown (A and B). Arrowhead indicates one of the high-molecular weight SUMO2/3 conjugates (HMW), which was desumoylated upon treatment of the cells with low concentrations of $\mathrm{H}_{2} \mathrm{O}_{2}$. Equal loading was determined using MAB anti- $\beta$-tubulin (Tub). Densitometry results for the level of HMW SUMO conjugates are shown from three independent experiments after normalization to tubulin. 
$\mathrm{H}_{2} \mathrm{O}_{2}$ (Maheshwari et al. 2009). Furthermore, previous studies in somatic cells suggested different mechanisms that are responsible for changes in sumoylation following treatment with high and low $\mathrm{H}_{2} \mathrm{O}_{2}$ doses (Bossis \& Melchior 2006, Xu et al. 2008). Therefore, in this study, the pattern of sumoylation in testicular cells was compared at low and high concentrations of $\mathrm{H}_{2} \mathrm{O}_{2}$. It was found that differently from the results obtained at a high concentration $(100 \mathrm{mM})$, at low concentrations (5-10 $\mu \mathrm{M})$ of $\mathrm{H}_{2} \mathrm{O}_{2}$, there was a decrease in the level of HMW SUMO2/3 and SUMO1 conjugates $(P<0.05)$. Figure $3 \mathrm{~A}$ shows the differential effects of $100 \mathrm{mM}$ and $10 \mu \mathrm{M} \mathrm{H}_{2} \mathrm{O}_{2}$ on SUMO2/3 conjugation, and Fig. 3B shows a decrease in SUMO1 conjugation at 5 and $10 \mu \mathrm{M}$ $\mathrm{H}_{2} \mathrm{O}_{2}$. At higher $\mathrm{H}_{2} \mathrm{O}_{2}$ concentrations $(1 \mathrm{mM}$ and above), there was an overall increase in the level of SUMO2/3 and SUMO1 conjugates, which seemed to be dose- and time-dependent.

\section{Analysis of sumoylation in vivo}

Oxidative stress and increased intrascrotal temperature have been related to many cases of testicular failures and male infertility (reviewed in Aitken \& Roman (2009)). Therefore, an important question from the results obtained in this study using testicular cells ex vivo was their relevance to SUMO-mediated stress response in vivo. To take an initial step in this direction, we used animals that were exposed for a 12-week period to tobacco smoke (see Materials and Methods). Previous studies reported tobacco smoke as a serious cause of oxidative damage in other tissues, but whether this occurs in the testis is mostly unknown. Although there were no significant changes detected in testicular weight following exposure to tobacco smoke, a significant decrease in the level of certain HMW SUMO conjugates was detected in exposed mice compared with the control animals (Fig. 4A and B for SUMO2/3 and SUMO1 respectively). Interestingly, for both SUMO isoforms, such a decrease resembled that seen after the treatment of testicular cells with low concentrations of $\mathrm{H}_{2} \mathrm{O}_{2}(5$ and $10 \mu \mathrm{M}$, Fig. $3 \mathrm{~A}$ and $\mathrm{B}$ ) and, therefore, suggested a low level of oxidative stress. Indeed, by comparing the samples from the two animal groups using Oxyblot analysis (which detects carbonyl groups introduced into protein side chains as a result of oxidative stress), an increased level of oxidation was detected for some $\mathrm{HMW}$ proteins in the tobacco smoke-exposed mice (Fig. 4C, arrowhead). A negative control for each sample was prepared using the reaction mixture without a derivatizing reagent (2,4-dinitrophenyl, DNP). Chemically derivatized markers $(M)$ served as a positive control for the western blot procedure. Interestingly, the changes in sumoylation preceded significant changes in cell viability as seen by the presence of uncleaved $116 \mathrm{kDa}$ isoform of PARP (an apoptotic protein undergoing cleavage into 89 and $24 \mathrm{kDa}$ fragments during apoptosis, Fig. 4, PARP). These findings suggest that changes in sumoylation serve as an early marker of oxidative stress in testicular cells.
A

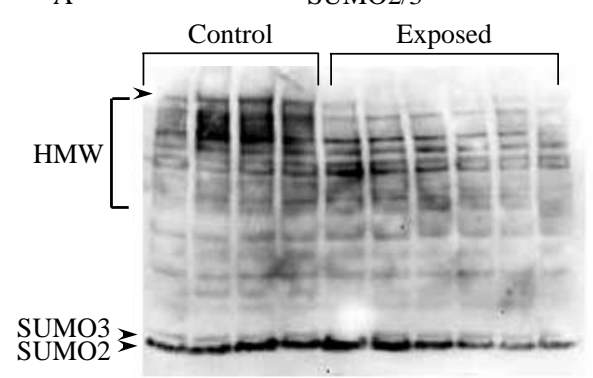

B

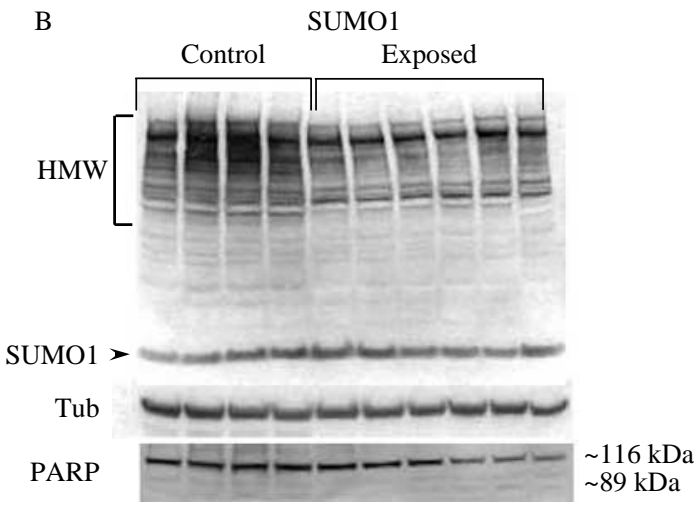

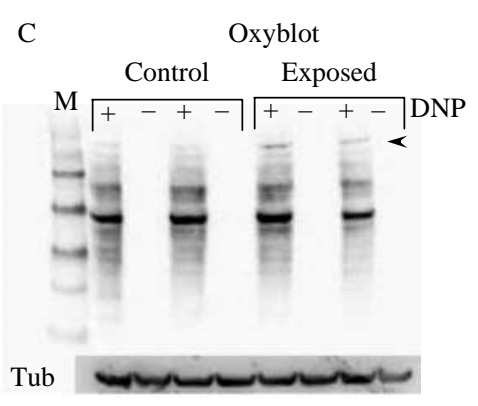

Figure 4 Effects of tobacco smoke on sumoylation and protein oxidation in testicular cells. Mice were exposed to tobacco smoke for a 12-week period as described in Materials and Methods. Whole cell lysates from testicular cells of exposed and control animals were prepared using NEM. Western blot analysis was performed using anti-SUMO2/3 (A) and SUMO1 (B) antibodies. The same protein samples were used for the Oxyblot analysis to detect the amount of carbonyl groups on cellular proteins which are introduced into protein side chains as a result of protein oxidation (C). Only two control and two exposed samples are shown, and a negative control without DNP-hydrazine (DNP, a derivatizing agent) was used for each sample. Western blotting was performed using an antibody specific to the DNP moiety of the proteins. Chemically derivatized molecular weight markers (M) served as positive controls. Changes in sumoylation of some high-molecular weight proteins (HMW) were consistent with their oxidative damage (arrowhead in $\mathrm{A}$ and $\mathrm{C}$ ). Equal loading was determined using MAB anti- $\beta$-tubulin (Tub). Changes in sumoylation preceded significant changes in cleavage of $116 \mathrm{kDa}$ PARP into 89 and $24 \mathrm{kDa}$ fragments (A, PARP). 


\section{SUMO1 localizes to DNA double-strand breaks in stressed germ cells and during meiotic recombination}

To confirm and expand the results obtained via western blotting, immunofluorescence analysis was performed using anti-SUMO antibodies and germ cells exposed to oxidative stress, as this type of stress caused the most notable changes in sumoylation. It is known that oxidative stress may cause DNA breaks; therefore, the cells were also co-labeled with a marker for DNA double-strand breaks, $\gamma$ (phosphorylated) H2AX. This analysis revealed that in addition to the previously described localization pattern of SUMO, in stress-induced cells, the protein was also localized to sites of DNA double-strand breaks. Figure 5A shows pachytene spermatocytes exposed to oxidative stress alongside control untreated cells. In control cells, SUMO1 and $\gamma \mathrm{H} 2 \mathrm{AX}$ were localized to the inactivated sex chromosome region (Fig. 5A, asterisk). A low level of SUMO1 was also detectable in centromeric heterochromatin as marked by intense DAPI staining (Fig. 5A, short arrows). In $\mathrm{H}_{2} \mathrm{O}_{2}$-treated cells, the formation of DNA breaks could clearly be seen as sites to which both $\gamma \mathrm{H} 2 \mathrm{AX}$ and SUMO1 clearly localized to produce a merged yellow signal (Fig. 5B $\mathrm{B}_{4}$, long arrows). SUMO in the centromeres is not co-localized with $\gamma \mathrm{H} 2 \mathrm{AX}$, but rather stained intensely with DAPI (short arrows). It was difficult to conclude whether SUMO2/3 was also present at the sites of DNA double-strand breaks because of the background caused by a high SUMO2/3 signal at centromeric heterochromatin (not shown).

The presence of SUMO at the sites of doublestrand DNA breaks further suggested its possible role in meiotic recombination, which is an event time when double-strand breaks precede synapsis of homologous chromosomes in spermatocytes. To test this hypothesis, an isolated cell bioimaging was performed using $\gamma \mathrm{H} 2 \mathrm{AX}$ signal in the whole nucleus as a marker of early spermatocytes, cells where massive double-strand DNA breaks are induced by meiotic recombination. Accepting an overexposure of the SUMO1 signal in the sex body, a low level of SUMO1 has been detected throughout the nucleus of early spermatocytes, where it was mostly co-localized with $\gamma \mathrm{H} 2 \mathrm{AX}$ at the sites of DNA double-strand breaks (Fig. 6).

\section{Discussion}

Defects in spermatogenesis can result in the formation of abnormal sperm, which can prevent fertilization and lead to birth defects. Various environmental factors such as elevated scrotal temperature and oxidative stress have been linked to abnormal spermatogenesis and infertility (Anderson et al. 1983, Emanuele \& Emanuele 1998, Lue et al. 2000, Rockett et al. 2001, Dare et al. 2002, Agarwal et al. 2003, Aitken \& Baker 2006, Gautam et al. 2007, Aitken \& Roman 2009, Shiraishi et al. 2010).
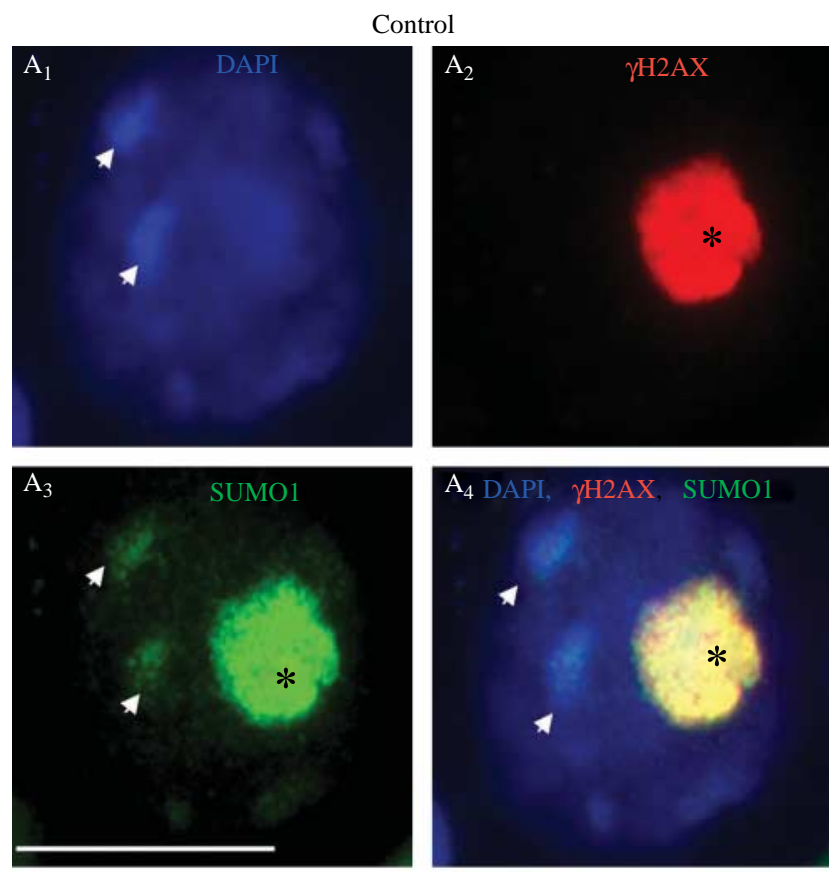

$20 \min \mathrm{H}_{2} \mathrm{O}_{2}$
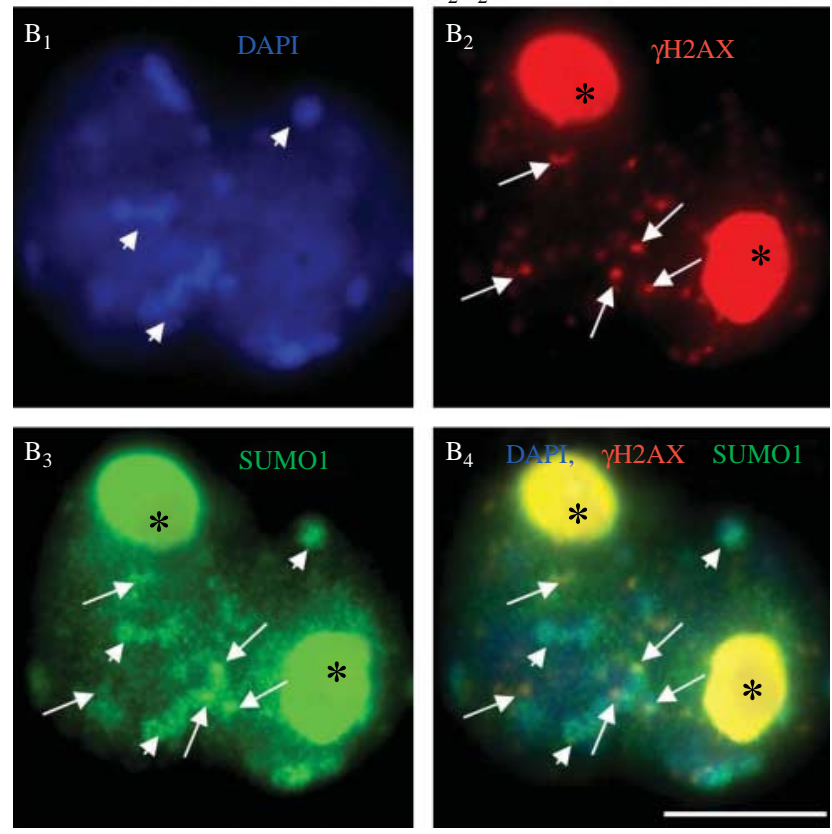

Figure 5 SUMO1 localizes to $\mathrm{H}_{2} \mathrm{O}_{2}$-induced DNA double-strand breaks in meiotic spermatocytes. Control $\left(\mathrm{A}_{1}-\mathrm{A}_{4}\right)$ and $\mathrm{H}_{2} \mathrm{O}_{2}$-treated (100 mM, 20 min $B_{1}-B_{4}$ ) spermatocytes were co-immunolabeled using anti- $\gamma \mathrm{H} 2 \mathrm{AX}$ (red) and anti-SUMO1 (green) antibodies. DAPI stains chromatin in blue. Centromeric heterochromatin is indicated by short arrows, the sex body region is indicated by an asterisk, and DNA double-strand breaks are indicated by long arrows. In $\mathrm{H}_{2} \mathrm{O}_{2}$-treated cells, the formation of DNA breaks could clearly be seen as sites where both $\gamma \mathrm{H} 2 \mathrm{AX}$ and SUMO1 localized producing a merged yellow signal $\left(\mathrm{B}_{4}\right.$, long arrows). SUMO in the centromeres is not co-localized with with $\gamma \mathrm{H} 2 \mathrm{AX}$, but it is intensely stained with DAPI (short arrows). The scale bar is $10 \mu \mathrm{m}$. 

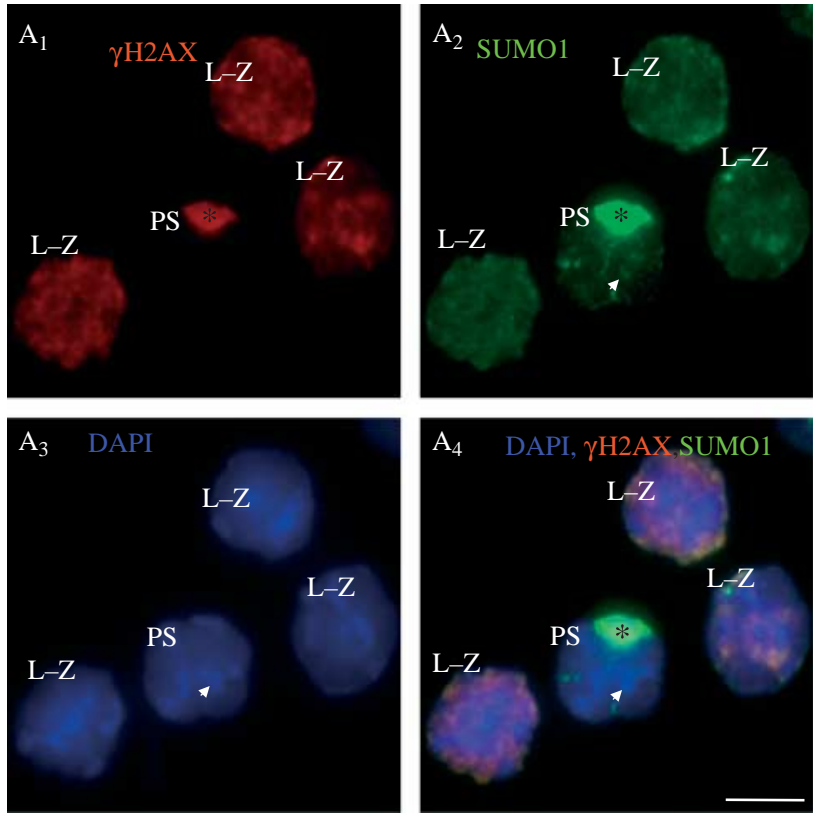

Figure 6 SUMO1 is detectable at the DNA double-strand breaks during meiotic recombination. Leptotene-zygotene spermatocytes $(\mathrm{L}-\mathrm{Z})$ were identified by the presence of massive DNA double-strand breaks in the whole nucleus, sites to which both $\gamma \mathrm{H} 2 \mathrm{AX}$ (red) and SUMO1 (green) were localized. Pachytene spermatocytes (PS) were characterized by the presence of the fully formed sex body region in which $\gamma \mathrm{H} 2 \mathrm{AX}$ and SUMO1 were seen co-localized (asterisk). In PS, SUMO1 was also detectable at a low level at centromeric heterochromatin as indicated by small arrows. The scale bar is $10 \mu \mathrm{m}$.

Since their discovery, SUMO proteins have been actively studied during the last decade. Studies in somatic cells specifically implicated SUMO2/3 and not SUMO1 in global sumoylation of cellular proteins following oxidative, osmotic, and heat stresses. SUMOs have been recently localized in different germ and somatic testicular cells, but their role during spermatogenesis as well as the targets of sumoylation in the testis are currently unknown. The results provide evidence about important roles of different SUMO isoforms in stress responses in germ cells in vitro and in vivo. Furthermore, this study identified TOP2A as one of the possible targets of sumoylation in testicular cells.

It has been suggested that the level of free SUMO1 is limited in somatic cells compared with the levels of SUMO2/3 (Saitoh \& Hinchey 2000). In contrast to these observations, using testicular cells and the antibodies employed in this study, the level of SUMO1 was comparable to that of SUMO2/3, and both the isoforms were involved in stress-mediated response. Interestingly, the stress-induced SUMO changes mostly affected the levels of free SUMO1 and SUMO2, while small or no changes were detected in the level of free SUMO3. Similar changes in stress-induced sumoylation were obtained in Arabidopsis (Kurepa et al. 2003), suggesting an evolutionarily conserved specific role for SUMO1 and $\mathrm{SUMO} 2$ in stress response.
Sumoylation of topoisomerases has been implicated both in normal cell functions and in response to stress. The family plays an important role in mitotic chromosome structure and centromeric cohesion, which is down-regulated through TOP2 sumoylation (Azuma et al. 2003, 2005, Dasso 2008). Furthermore, certain genotoxic, oxidative, and heat shock stresses rapidly increased the level of SUMO TOP1 and SUMO TOP2 conjugates (Mao et al. 2000, Agostinho et al. 2008). A specific role of TOP2A in germ cells has been suggested, but whether the protein's activity in these cells is regulated by sumoylation remains unknown (Cobb et al. 1999). The results of this study provide evidence that such a regulation exists, and that TOP2A is sumoylated in the germ cells. SUMO and TOP2A show similar localization patterns in meiotic spermatocytes, suggesting an involvement of the two proteins in the regulation of the structure and dynamics of meiotic chromosomes. Further studies are needed to understand the functional role of sumoylation in the regulation of TOP2A as well as of other isoforms of the protein. One of the limitations of these studies is that only a small fraction of a protein is being sumoylated, thus making it difficult to see small changes in the level of the sumoylated protein (Tatham et al. 2009).

SUMO-conjugating and SUMO-deconjugating enzymes are highly sensitive to stresses caused by different stimuli. For example, high concentrations of $\mathrm{H}_{2} \mathrm{O}_{2}$ have been shown to inhibit the SUMO deconjugation machinery and, therefore, to cause global hypersumoylation (Saitoh \& Hinchey 2000). In contrast, low $\mathrm{H}_{2} \mathrm{O}_{2}$ concentrations first affect SUMO-conjugating enzymes, causing desumoylation (Bossis \& Melchior 2006). These findings are consistent in part with the results obtained in this study. New studies have also shown that sumoylation can serve as a marker for damaged cellular proteins that then undergo ubiquination and degradation (Geoffroy \& Hay 2009). In agreement with this possible role of sumoylation, in this study, a high concentration of $\mathrm{H}_{2} \mathrm{O}_{2}$ caused hypersumoylation of numerous $\mathrm{HMW}$ proteins. In support of this idea, overexpression of the chaperone HSP70 in Arabidopsis cells decreased the level of misfolded proteins and the number of stress-induced HMW SUMO conjugates (Kurepa et al. 2003).

Our experiments using mice exposed to tobacco smoke also supported this idea, as reduced sumoylation and increased oxidative damage of certain HMW proteins were shown in the testis of exposed animals compared with the controls. The results of this study also suggest that $\mathrm{CO}_{2}$ euthanasia causes a high level of SUMO-mediated stress response in cells. This finding is in agreement with the results of a new study, in which a significant increase in the level of stress markers was detected in the animal blood following a brief exposure to $\mathrm{CO}_{2}$ (Reed et al. 2009). 
Following oxidative stress, germ cells showed massive DNA breaks, to which both $\gamma \mathrm{H} 2 \mathrm{AX}$ and SUMOs were localized, a finding which has not been reported previously in germ cells. The presence of SUMO close to the sites of DNA breaks in germ cells suggests a role for sumoylation in either the formation or the repair of DNA double-strand beaks. Consistent with this suggested role of sumoylation, in nontesticular cells, an increasing number of proteins either directly involved with DNA damage repair or associated with the cellular response to DNA damage are activated by sumoylation (Bergink \& Jentsch 2009).

In agreement with the results described above, for the first time in this study, SUMO1 was also detected at the sites of DNA double-strand breaks preceding meiotic recombination. Previous confocal studies by our group failed to detect SUMO1 in the nucleus of early spermatocytes using intact seminiferous tubules, although based on its localization dynamics that is similar to that of other DNA repair proteins during the zygotene and pachytene stages, such localization has been suggested (Vigodner 2009). As seen in Figs 5 and 6, the level of SUMO at double-strand breaks was low compared with the amount of the protein in the sex body, so an overexposure of the sex body signal had to be accepted to detect the protein in other regions of meiotic spermatocytes. This study also employed different and apparently more sensitive anti-SUMO1 antibodies than the confocal studies. Furthermore, although the isolated cell bioimaging used in this study lacked the ability to observe numerous spermatocytes from the same development stage compared with confocal microscopy, in some cases, it gave a higher sensitivity at the level of an individual cell, as cells were not imaged within the tissue. Nevertheless, despite big advances in the field, germ cell immunofluorescence techniques still have some limitations, including different fixation and staining techniques, specificity of available antibodies and their sensitivity. These differences can cause differently interpreted results. For example, the first localization study in humans detected SUMO on the sex chromosomes of some meiotic spermatocytes, and another study argued such localization (Vigodner et al. 2006, Metzler-Guillemain et al. 2008). However, the last study failed to detect any signal along synaptonemal complexes in pachytene spermatocytes, while another group demonstrated such localization and suggested synaptonemal complex proteins as possible sumoylated targets (Brown et al. 2008, Metzler-Guillemain et al. 2008). Therefore, given these limitations and the complexity of SUMO regulation, various approaches, including the analysis of SUMO proteins in transgenic animals where specific genes regulating meiotic prophase have been inactivated, should be used to unravel the roles that SUMO proteins play during spermatogenesis. Further studies will also be aimed to identify and characterize cell-specific targets of SUMO in the testis, especially those that show changes in their expression upon stress, toxic exposure, or other pathological conditions. Together, these studies will lead to a better understanding of spermatogenesis and the causes of male infertility, and they may provide new insights into the role of sumoylation in other tissues and organs.

\section{Materials and Methods \\ Experimental cell lines, laboratory animals, and antibodies}

Spermatogonia (GC-1) and Sertoli (15P1) cell lines were obtained from the American Type Tissue Culture (Manassas, VA, USA). The GC-1 cells were derived from type B spermatogonia, and they express two testis-specific isoproteins, cytochrome $c$, and lactate dehydrogenase C4 (Hofmann et al. 1992). Transplanted GC-1 cells were capable of differentiating into spermatids in an in vivo microenvironment (Wang et al. 2009). The 15P1 cell line exhibits some characteristics of Sertoli cells, including their transcription of Wilms' tumor (Wt1) and Kitl (Steel) genes (Rassoulzadegan et al. 1993), and their phagocytic activity (Grandjean et al. 1997). The cells also express KITL $(\mathrm{KL})$ protein, a ligand of the KIT receptor, which is also expressed in Sertoli cells (Vincent et al. 1998, Vidal et al. 2001). Cells were cultured in DMEM supplemented with $10 \%$ fetal bovine serum, and the GC- 1 cells were incubated at $37^{\circ} \mathrm{C}$ and the $15 \mathrm{P} 1$ cells $\left(5 \% \mathrm{CO}_{2}\right)$ at $32{ }^{\circ} \mathrm{C}$.

Adult male C57B16 mice were obtained from the Jackson Laboratory (Bar Harbor, ME, USA). Animals were housed in standard lighting (12 h light:12 h darkness), and they had access to food and water ad libitum. They were maintained in facilities approved by the American Association for the Accreditation of Laboratory Animal Care. Procedures involving the use of animals strictly followed the Guidelines for Care and Use of Laboratory Animals set forth by the NIH.

Mice were killed by $\mathrm{CO}_{2}$ asphyxiation. Testes were surgically excised, and tunica albuginea, remains of fat and connective tissue were removed. A single cell suspension was prepared by mincing the testes with surgical scissors in $1 \mathrm{cc}$ of cold PBS (5 min, RT). PBS was added to the final volume of $5 \mathrm{cc}$, and tubule fragments were mechanically dissociated using Pasteur pipettes. The cells were filtered through a nylon mesh (100 micron, Small Parts), and kept on ice. A portion of the cells was used immediately to prepare cell lysates. Another portion was incubated at $32{ }^{\circ} \mathrm{C}$ in complete DMEM for $2-3 \mathrm{~h}$ until stress and drug treatment.

Testicles from mice of different ages $(7,18,21,23$, and 28 days post partum) were obtained from the Jackson Laboratory. Tissues were snap frozen in liquid nitrogen immediately after excision, shipped on dry ice, and kept at $-80{ }^{\circ} \mathrm{C}$ until the analysis.

Rabbit polyclonal antibodies against SUMO2/3 and SUMO1 were purchased from Abcam (Cambridge, MA, USA). A MAB against phosphorylated histone $\mathrm{H} 2 \mathrm{AX}$ (Ser139, $\gamma \mathrm{H} 2 \mathrm{AX}$ ) was purchased from Upstate Cell Signaling Solutions (Lake Placid, NY, USA). Rabbit polyclonal antibodies against TOP2A were purchased from Abcam and Cell Signaling (Boston, MA, USA). All remaining reagents were purchased from Sigma, unless otherwise noted. 


\section{Stress and drug treatment}

About $10^{7}$ cells were gently centrifuged, the pellet was resuspended in $100 \mu \mathrm{l}$ of serum-free medium, and the cells were subjected to $100 \mathrm{mM} \mathrm{H}_{2} \mathrm{O}_{2}$, or $7 \%$ ethanol stress for $20 \mathrm{~min}$. For heat stress, cells were incubated at $43{ }^{\circ} \mathrm{C}$ for 20 min (Saitoh \& Hinchey 2000). Experiments with low doses of $\mathrm{H}_{2} \mathrm{O}_{2}$ were performed for $1 \mathrm{~h}$ (Maheshwari et al. 2009).

The treatments were followed by preparation of whole cell protein lysates and slides. Each experiment was repeated four times.

\section{Protein extraction and western blot analysis of SUMO expression}

Following the application of cellular stress, whole cell protein lysates were prepared using the Whole Cell Extraction Kit and Protease Inhibitor Cocktail (Chemicon, Temecula, CA, USA) according to the manufacturer's instructions with or without isopeptidase inhibitor NEM (20 mM, prevents cleavage of SUMO from modified proteins). Cellular debris was pelleted by centrifugation, and protein concentrations were determined with the bichromic acid protein assay using BSA as the standard (Pierce, Rockford, IL, USA).

Proteins $(30 \mu \mathrm{g}$ each) were mixed with a sample buffer containing NuPAGE reducing agent (Invitrogen), and heated for $10 \mathrm{~min}$ at $70^{\circ} \mathrm{C}$. Gel electrophoresis, under reducing conditions, was performed using NuPAGE $4-12 \%$ bis-Tris polyacrylamide gels and MOPS running buffer (Invitrogen) at a constant $200 \mathrm{~V}$. After electrophoresis, proteins were transferred onto a nitrocellulose membrane $(0.45 \mu \mathrm{m}$, Invitrogen) using NuPAGE transfer buffer. Protein electrophoresis and transfer were performed using Invitrogen's XCell SureLock Mini-Cell Electrophoresis system. Western blotting was performed using the Western Breeze Chemiluminescent Immunodetection Kit (Invitrogen) or ECL plus kit (GE Healthcare, Piscataway, NJ, USA) following the user's manual. SUMO1 or SUMO2/3 antibody was used at a 1:500 dilution in $1 \%$ PBS/BSA and $0.1 \%$ sodium azide. Equal loading was determined using $M A B$ anti- $\beta$-tubulin (1:2000; Invitrogen). Quantitative analysis was performed using Quantity one program (Bio-Rad Laboratories). Densitometry results obtained from three experiments are shown after normalization to tubulin.

\section{Co-immunoprecipitation}

About $500 \mu \mathrm{g}$ of proteins were incubated with antibodies against SUMO (Abcam, 1:50 final dilution) or TOP2A (Cell Signaling, 1:20 final dilution) for $2 \mathrm{~h}$ at $4{ }^{\circ} \mathrm{C}$. The antigenantibody complexes were captured with a mixture of $50 \mu \mathrm{l}$ of Protein G beads ( $50 \%$ slurry) and $50 \mu$ of Protein A beads $(30 \%$ slurry) for $1 \mathrm{~h}$ at $4{ }^{\circ} \mathrm{C}$. The precipitated complexes were washed by centrifugation three times with whole cell extraction buffer (15 mM NEM) and one time with PBS. Proteins were released from the beads by boiling in the sample buffer $\left(5 \mathrm{~min}, 90^{\circ} \mathrm{C}\right.$ ), and were subjected to electrophoresis followed by western blot analyses.

\section{Detection of protein oxidation}

An OxyBlot kit (Millipore, Billerica, MA, USA) was used to immunodetect carbonyl groups (which are introduced into protein side chains as a result of protein oxidation) according to the user's manual. Briefly, to derivatize the carbonyl groups to DNP-hydrazone, cell lysates $(\sim 10 \mu \mathrm{g})$ were treated with DNP-hydrazine for $15 \mathrm{~min}$ at room temperature, and were then neutralized using the neutralization buffer provided with the kit. A negative control without DNP-hydrazine was used in each experiment. Proteins were then separated on $4-12 \%$ NUPAGE gels and transferred onto nitrocellulose membranes as described above. Western blotting was performed using an antibody specific to the DNP moiety of the proteins. Chemically derivatized molecular weight markers served as the positive controls. Equal loading was determined using MAB anti- $\beta$-tubulin (1:2000; Invitrogen).

\section{Fixation and immunofluorescence analysis using SUMO antibodies}

To inhibit cell recovery from stress, cells were immediately fixed in $1 \%$ paraformaldehyde. The cells were then attached to glass microscope slides using cytocentrifugation and washed three times in PBS.

Fixed cells on the slides were treated for $10 \mathrm{~min}$ with $0.3 \%$ Igepal (NP-40; Sigma) and pre-blocked for $30 \mathrm{~min}$ with ImageIT FX Signal Enhancer (Molecular Probes, Eugene, OR, USA). Cells were rinsed with PBS and incubated with a mixture of either anti-SUMO1 or anti-SUMO2/3 antibody and phosphorylated histone $\mathrm{H} 2 \mathrm{AX}$ (Ser139, $\gamma \mathrm{H} 2 \mathrm{AX}$ ), at final dilutions of 1:150 and $1: 400$ in $\mathrm{PBS} / 1 \% \mathrm{BSA}$ for SUMO and $\gamma \mathrm{H} 2 \mathrm{AX}$ respectively. Following one wash with PBS, the cells were incubated with Alexa Fluor 488-conjugated goat anti-rabbit IgG (Molecular Probes) and Texas Red goat anti-mouse IgG (Vector Laboratories, Burlingame, CA, USA) at a 1:150 dilution in PBS containing 1\% BSA, and were then washed three times. Topoisomerase immunostaining was performed using antiTOP2A antibody (Abcam) followed by incubation with Alexa Fluor 488-conjugated goat anti-rabbit IgG. Cell nuclei were stained for $5 \mathrm{~min}$ with $4 \mu \mathrm{g} / \mathrm{ml}$ of DAPI, and were then rinsed with PBS. The slides were mounted using ProLong Antifade Kit (Molecular Probes). Images were collected using a Nikon inverted fluorescent microscope, a $40 \times$ lens, and DAPI, FITC, and CY-5 filter sets. At least 50 cells were analyzed.

\section{Smoke exposure}

The tobacco smoke exposure was performed in the laboratory of Dr Jeanine D'Armiento, Division of Molecular Medicine, Columbia University, New York. Mice were exposed to cigarette smoke in a specially designed chamber for $5 \mathrm{~h}$ /day for 5 days a week for 12 weeks. Two 70-ml puffs per minute from research cigarettes (Type 2RF; Tobacco Health Research Institute, Lexington, KY, USA) were generated by a smoking machine (Teague Enterprises, Davis, CA, USA), and were then diluted with fresh air and delivered to the whole body exposure chambers. Detailed protocols are available (Foronjy et al. 2006). 


\section{Declaration of interest}

The authors declare that there is no conflict of interest that could be perceived as prejudicing the impartiality of the research reported.

\section{Funding}

This study was supported in part by a grant from the Flight Attendant Medical Research Institute (to M Vigodner).

\section{Acknowledgements}

The authors thank Stern College for Women, Yeshiva University, and Joseph Alexander Foundation for supporting this research project. The authors also thank Dr Jeanine D'Armiento, Division of Molecular Medicine, Columbia University, New York, for performing the tobacco smoke exposure of mice.

\section{References}

Agarwal A, Saleh RA \& Bedaiwy MA 2003 Role of reactive oxygen species in the pathophysiology of human reproduction. Fertility and Sterility $\mathbf{7 9}$ 829-843.

Agarwal A, Said TM, Bedaiwy MA, Banerjee J \& Alvarez JG 2006 Oxidative stress in an assisted reproductive techniques setting. Fertility and Sterility 86 503-512.

Agostinho M, Santos V, Ferreira F, Costa R, Cardoso J, Pinheiro I, Rino J, Jaffray E, Hay RT \& Ferreira J 2008 Conjugation of human topoisomerase $2 \alpha$ with small ubiquitin-like modifiers $2 / 3$ in response to topoisomerase inhibitors: cell cycle stage and chromosome domain specificity. Cancer Research 68 2409-2418.

Aitken RJ \& Baker MA 2006 Oxidative stress, sperm survival and fertility control. Molecular and Cellular Endocrinology 250 66-69.

Aitken RJ \& De luliis GN 2007 Origins and consequences of DNA damage in male germ cells. Reproductive Biomedicine Online 14 727-733.

Aitken RJ \& Roman SD 2009 Antioxidant systems and oxidative stress in the testes. Advances in Experimental Medicine and Biology 636 154-171.

Aitken RJ, Baker MA \& Sawyer D 2003 Oxidative stress in the male germ line and its role in the aetiology of male infertility and genetic disease. Reproductive Biomedicine Online 7 65-70.

Anderson RA Jr, Willis BR, Oswald C \& Zaneveld LJ 1983 Ethanol-induced male infertility: impairment of spermatozoa. Journal of Pharmacology and Experimental Therapeutics 225 479-486.

Ayaydin F \& Dasso M 2004 Distinct in vivo dynamics of vertebrate SUMO paralogues. Molecular Biology of the Cell 15 5208-5218.

Azuma Y, Arnaoutov A \& Dasso M 2003 SUMO-2/3 regulates topoisomerase II in mitosis. Journal of Cell Biology 163 477-487.

Azuma Y, Arnaoutov A, Anan T \& Dasso M 2005 PIASy mediates SUMO-2 conjugation of topoisomerase-II on mitotic chromosomes. EMBO Journal $242172-2182$.

Bergink S \& Jentsch S 2009 Principles of ubiquitin and SUMO modifications in DNA repair. Nature 458 461-467.

Bohren KM, Nadkarni V, Song JH, Gabbay KH \& Owerbach D 2004 A M55V polymorphism in a novel SUMO gene (SUMO-4) differentially activates heat shock transcription factors and is associated with susceptibility to type I diabetes mellitus. Journal of Biological Chemistry 279 27233-27238.

Bossis G \& Melchior F 2006 Regulation of SUMOylation by reversible oxidation of SUMO conjugating enzymes. Molecular Cell 21 349-357.

Brown PW, Hwang K, Schlegel PN \& Morris PL 2008 Small ubiquitinrelated modifier (SUMO)-1, SUMO-2/3 and SUMOylation are involved with centromeric heterochromatin of chromosomes 9 and 1 and proteins of the synaptonemal complex during meiosis in men. Human Reproduction 23 2850-2857.
Chupreta S, Holmstrom S, Subramanian L \& Iniguez-Lluhi JA 2005 A small conserved surface in SUMO is the critical structural determinant of its transcriptional inhibitory properties. Molecular and Cellular Biology 25 4272-4282.

Cobb J, Miyaike M, Kikuchi A \& Handel MA 1999 Meiotic events at the centromeric heterochromatin: histone H3 phosphorylation, topoisomerase II $\alpha$ localization and chromosome condensation. Chromosoma 108 412-425.

Dare WN, Noronha CC, Kusemiju OT \& Okanlawon OA 2002 The effect of ethanol on spermatogenesis and fertility in male Sprague-Dawley rats pretreated with acetylsalicylic acid. Nigerian Postgraduate Medical Journal 9 194-198.

Dasso M 2008 Emerging roles of the SUMO pathway in mitosis. Cell Division 35.

Dohmen RJ 2004 SUMO protein modification. Biochimica et Biophysica Acta 1695 113-131.

Emanuele MA \& Emanuele NV 1998 Alcohol's effects on male reproduction. Alcohol Health \& Research World 22 195-201.

Foronjy RF, Mirochnitchenko $O$, Propokenko $O$, Lemaitre $V$, Jia $Y$, Inouye M, Okada Y \& D'Armiento JM 2006 Superoxide dismutase expression attenuates cigarette smoke- or elastase-generated emphysema in mice. American Journal of Respiratory and Critical Care Medicine 173 623-631.

Gautam DK, Misro MM, Chaki SP, Chandra M \& Sehgal N 2007 hCG treatment raises $\mathrm{H}_{2} \mathrm{O}_{2}$ levels and induces germ cell apoptosis in rat testis. Apoptosis 12 1173-1182.

Geiss-Friedlander R \& Melchior F 2007 Concepts in sumoylation: a decade on. Nature Reviews. Molecular Cell Biology 8 947-956.

Geoffroy MC \& Hay RT 2009 An additional role for SUMO in ubiquitinmediated proteolysis. Nature Reviews. Molecular Cell Biology 10 564-568.

Gill G 2004 SUMO and ubiquitin in the nucleus: different functions, similar mechanisms? Genes and Development 18 2046-2059.

Golebiowski F, Matic I, Tatham MH, Cole C, Yin Y, Nakamura A, Cox J, Barton GJ, Mann M \& Hay RT 2009 System-wide changes to SUMO modifications in response to heat shock. Science Signaling 2 ra24.

Grandjean V, Sage J, Ranc F, Cuzin F \& Rassoulzadegan M 1997 Stagespecific signals in germ line differentiation: control of Sertoli cell phagocytic activity by spermatogenic cells. Developmental Biology 184 165-174.

Hietakangas V, Anckar J, Blomster HA, Fujimoto M, Palvimo JJ, Nakai A \& Sistonen L 2006 PDSM, a motif for phosphorylation-dependent SUMO modification. PNAS 103 45-50.

Hofmann MC, Narisawa S, Hess RA \& Millan JL 1992 Immortalization of germ cells and somatic testicular cells using the SV40 large T antigen. Experimental Cell Research 201 417-435.

Kerscher O 2007 SUMO junction - what's your function? New insights through SUMO-interacting motifs EMBO Reports 8 550-555.

Kurepa J, Walker JM, Smalle J, Gosink MM, Davis SJ, Durham TL, Sung DY \& Vierstra RD 2003 The small ubiquitin-like modifier (SUMO) protein modification system in Arabidopsis. Accumulation of SUMO1 and -2 conjugates is increased by stress. Journal of Biological Chemistry $\mathbf{2 7 8}$ 6862-6872.

La Salle S, Sun F, Zhang XD, Matunis MJ \& Handel MA 2008 Developmental control of sumoylation pathway proteins in mouse male germ cells. Developmental Biology 321 227-237.

Li M, Guo D, Isales CM, Eizirik DL, Atkinson M, She JX \& Wang CY 2005 SUMO wrestling with type 1 diabetes. Journal of Molecular Medicine 83 504-513.

Lin DY, Huang YS, Jeng JC, Kuo HY, Chang CC, Chao TT, Ho CC, Chen YC, Lin TP, Fang HI et al. 2006 Role of SUMO-interacting motif in Daxx SUMO modification, subnuclear localization, and repression of sumoylated transcription factors. Molecular Cell 24 341-354.

Lue YH, Hikim AP, Swerdloff RS, Im P, Taing KS, Bui T, Leung A \& Wang C 1999 Single exposure to heat induces stage-specific germ cell apoptosis in rats: role of intratesticular testosterone on stage specificity. Endocrinology 140 1709-1717.

Lue Y, Hikim AP, Wang C, Im M, Leung A \& Swerdloff RS 2000 Testicular heat exposure enhances the suppression of spermatogenesis by testosterone in rats: the "two-hit" approach to male contraceptive development. Endocrinology 141 1414-1424. 
Maheshwari A, Misro MM, Aggarwal A, Sharma RK \& Nandan D 2009 Pathways involved in testicular germ cell apoptosis induced by $\mathrm{H}_{2} \mathrm{O}_{2}$ in vitro. FEBS Journal 276 870-881.

Mao Y, Okada S, Chang LS \& Muller MT 2000 p53 dependence of topoisomerase I recruitment in vivo. Cancer Research 60 4538-4543.

Matunis MJ, Coutavas E \& Blobel G 1996 A novel ubiquitin-like modification modulates the partitioning of the Ran-GTPase-activating protein RanGAP1 between the cytosol and the nuclear pore complex. Journal of Cell Biology 135 1457-1470.

Metzler-Guillemain C, Depetris D, Luciani JJ, Mignon-Ravix C, Mitchell MJ \& Mattei MG 2008 In human pachytene spermatocytes, SUMO protein is restricted to the constitutive heterochromatin. Chromosome Research 16 761-782.

Muller S, Ledl A \& Schmidt D 2004 SUMO: a regulator of gene expression and genome integrity. Oncogene 23 1998-2008.

Muthusami KR \& Chinnaswamy P 2005 Effect of chronic alcoholism on male fertility hormones and semen quality. Fertility and Sterility 84 919-924.

Rassoulzadegan M, Paquis-Flucklinger V, Bertino B, Sage J, Jasin M, Miyagawa K, van Heyningen V, Besmer P \& Cuzin F 1993 Transmeiotic differentiation of male germ cells in culture. Cell 75 997-1006.

Reed B, Varon J, Chait BT \& Kreek MJ 2009 Carbon dioxide-induced anesthesia results in a rapid increase in plasma levels of vasopressin. Endocrinology 150 2934-2939.

Rockett JC, Mapp FL, Garges JB, Luft JC, Mori C \& Dix DJ 2001 Effects of hyperthermia on spermatogenesis, apoptosis, gene expression, and fertility in adult male mice. Biology of Reproduction 65 229-239.

Rogers RS, Inselman A, Handel MA \& Matunis MJ 2004 SUMO modified proteins localize to the XY body of pachytene spermatocytes. Chromosoma 113 233-243.

Saitoh H \& Hinchey J 2000 Functional heterogeneity of small ubiquitinrelated protein modifiers SUMO-1 versus SUMO-2/3. Journal of Biological Chemistry 275 6252-6258.

Shiraishi K, Takihara H \& Matsuyama H 2010 Elevated scrotal temperature, but not varicocele grade, reflects testicular oxidative stress-mediated apoptosis. World Journal of Urology [in press]. DOI:10.1007/s00345009-0462-5.

Sikka SC 1996 Oxidative stress and role of antioxidants in normal and abnormal sperm function. Frontiers in Bioscience 1 e78-e86.

Song J, Durrin LK, Wilkinson TA, Krontiris TG \& Chen Y 2004 Identification of a SUMO-binding motif that recognizes SUMO-modified proteins. PNAS 101 14373-14378.

Song J, Zhang Z, Hu W \& Chen Y 2005 Small ubiquitin-like modifier (SUMO) recognition of a SUMO binding motif: a reversal of the bound orientation. Journal of Biological Chemistry $28040122-40129$.
Tatham MH, Rodriguez MS, Xirodimas DP \& Hay RT 2009 Detection of protein SUMOylation in vivo. Nature Protocols 4 1363-1371.

Tempe D, Piechaczyk M \& Bossis G 2008 SUMO under stress. Biochemical Society Transactions 36 874-878.

Vidal F, Lopez P, Lopez-Fernandez LA, Ranc F, Scimeca JC, Cuzin F \& Rassoulzadegan M 2001 Gene trap analysis of germ cell signaling to Sertoli cells: NGF-TrkA mediated induction of Fra1 and Fos by postmeiotic germ cells. Journal of Cell Science 114 435-443.

Vigodner M 2009 Sumoylation precedes accumulation of phosphorylated $\mathrm{H} 2 \mathrm{AX}$ on sex chromosomes during their meiotic inactivation. Chromosome Research 17 37-45.

Vigodner M \& Morris PL 2005 Testicular expression of small ubiquitinrelated modifier-1 (SUMO-1) supports multiple roles in spermatogenesis: silencing of sex chromosomes in spermatocytes, spermatid microtubule nucleation, and nuclear reshaping. Developmental Biology 282 480-492.

Vigodner M, Ishikawa T, Schlegel PN \& Morris PL 2006 SUMO-1, human male germ cell development, and the androgen receptor in the testis of men with normal and abnormal spermatogenesis. American Journal of Physiology. Endocrinology and Metabolism 290 E1022-E1033.

Vincent S, Segretain D, Nishikawa S, Nishikawa SI, Sage J, Cuzin F \& Rassoulzadegan M 1998 Stage-specific expression of the Kit receptor and its ligand $(\mathrm{KL})$ during male gametogenesis in the mouse: a Kit-KL interaction critical for meiosis. Development 125 4585-4593.

Wang Y, Song W, Li S, Guan X, Miao S, Zong S, Koide SS \& Wang L 2009 GC-1 mRHBDD1 knockdown spermatogonia cells lose their spermatogenic capacity in mouse seminiferous tubules. BMC Cell Biology 1025.

Xu Z, Lam LS, Lam LH, Chau SF, Ng TB \& Au SW 2008 Molecular basis of the redox regulation of $S U M O$ proteases: a protective mechanism of intermolecular disulfide linkage against irreversible sulfhydryl oxidation. FASEB Journal 22 127-137.

Zhang FP, Mikkonen L, Toppari J, Palvimo JJ, Thesleff I \& Janne OA 2008 Sumo-1 function is dispensable in normal mouse development. Molecular and Cellular Biology 28 5381-5390.

Zhao J 2007 Sumoylation regulates diverse biological processes. Cellular and Molecular Life Sciences 64 3017-3033.

Received 4 November 2009

First decision 8 December 2009

Revised manuscript received 25 March 2010

Accepted 12 April 2010 